\title{
Strategy for Advancement of IRP in Public Power
}

\section{Volume 1: IRP Advancement Strategy}

Cynthia J. Garrick Garrick \& Associates Morrison, Colorado

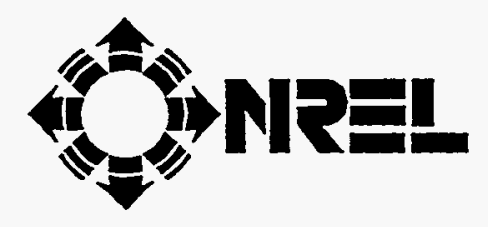

National Renewable Energy Laboratory 1617 Cole Boulevard

- Golden, Colorado 80401-3393

A national laboratory of the U.S. Department of Energy Managed by Midwest Research Institute for the U.S. Department of Energy under Contract No. DE-AC36-83CH10093 


\section{Strategy for Advancement of IRP in Public Power \\ Volume 1: IRP Advăncement Strategies}

NREL Technical Monitor: Paul Galen

Cynthia J. Garrick

Garrick \& Associates

Morrison, Colorado

National Renewable Energy Laboratory

1617 Cole Boulevard

Golden, Colorado 80401-3393

A national laboratory of the

U.S. Department of Energy

Managed by Midwest Research Institute

for the U.S. Department of Energy

under Contract No. DE-AC36-83CH10093

Prepared under Subcontract No. AAW-3-13353-01

October 1995 


\section{NOTICE}

This report was prepared as an account of work sponsored by an agency of the United States government. Neither the United States government nor any agency thereof, nor any of their employees, makes any warranty, express or implied, or assumes any legal liability or responsibility for the accuracy, completeness, or usefulness of any information, apparatus, product, or process disclosed, or represents that its use would not infringe privately owned rights. Reference herein to any specific commercial product, process, or service by trade name, trademark, manufacturer, or otherwise does not necessarily constitute or imply its endorsement, recommendation, or favoring by the United States government or any agency thereof. The views and opinions of authors expressed herein do not necessarily state or reflect those of the United States government or any agency thereof.

Available to DOE and DOE contractors from:

Office of Scientific and Technical Information (OSTI)

P.O. Box 62

Oak Ridge, TN 37831

Prices available by calling (615) 576-8401

Available to the public from:

National Technical Information Service (NTIS)

U.S. Department of Commerce

5285 Port Royal Road

Springfield, VA 22161

(703) $487-4650$ 


\section{Acknowledgments}

We would like to express gratitude and appreciation for the contributions of the Advancement of IRP in Public Power Steering Committee, including Barry Moline of the American Public Power Association; Mike Bull and Erik Westman of the Bonneville Power Administration; Rob Church and Mike Oldak of the National Rural Electric Cooperative Association; Georg Shultz of the Rural Electrification Administration; Bill Stewart, Kim Ledbetter, and Al Pless of Southeastern Power Administration; Jerry Martin of Southwestern Power Administration; Dr. Lynn Maxwell of the Tennessee Valley Authority; and Theresa Williams and Randy Manion of Western Area Power Administration.

We thank the American Public Power Association (APPA) for sponsoring the IRP survey for publicly owned utilities and the Rural Electrification Administration and the National Rural Electric Cooperative Association for helping develop and implement the cooperative survey. The findings from these surveys were critical to the definition of the IRP Advancement Strategy.

A number of NREL personnel were key contributors to the IRP Advancement Strategy development. Tom Holt provided extensive ongoing project support, including performing the Technical and Economic Market Characterization (Appendix D) and assisting with the cooperative survey. Jan Eckert's perseverance in obtaining information regarding state IRP policies is evident in Appendix C. In addition, Dan Packey provided valuable assistance in designing the survey samples, and Dee Schafer's administrative support was responsive and helpful, as always.

Finally, we thank Bob San Martin and Andrew Krantz of DOE's Office of Utility Technologies for their dedicated interest in, and continued support of, the advancement of IRP for public utilities. Their valuable input has helped to focus and shape the strategy presented herein. 


\section{Contents}

\section{Volume 1: IRP Advancement Strategy}

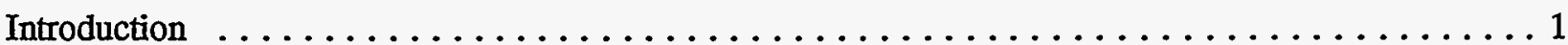

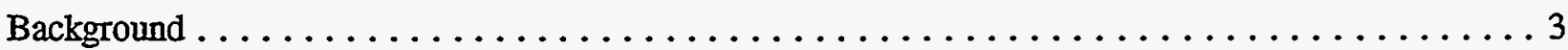

Advancement Needs . . . . . . . . . . . . . . . . . . . . . . . . . 5

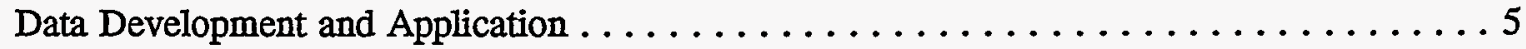

Analysis Tools . . . . . . . . . . . . . . . . . . . . . . . . 6

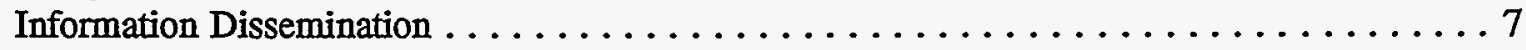

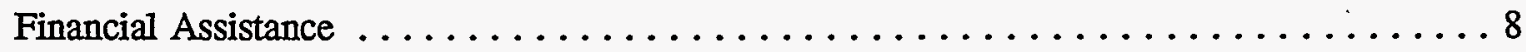

Technical Assistance ..........................

Other Needs . . . . . . . . . . . . . . . . . . . . . . . . . 9

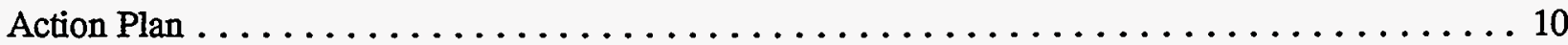

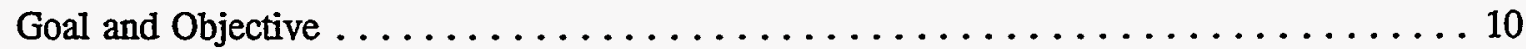

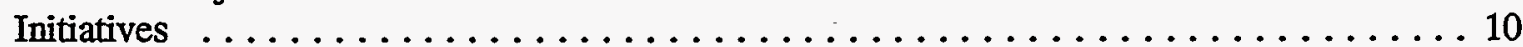

Resources ................................... 11

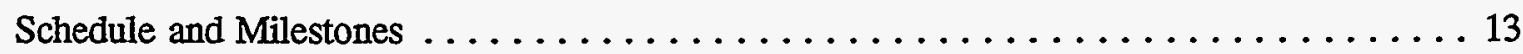

\section{Volume 2: Technical Appendices}

Appendix A: Needs Assessment Summary Report . . . . . . . . . . . . . . . A-1

Appendix B: Public Power Survey . . . . . . . . . . . . . . . . . . . . B-1

Appendix C: Federal and State IRP Policies . . . . . . . . . . . . . . . . C-1

Appendix D: Technical and Economic Market Characterization . . . . . . . . . . . D-1

\section{List of Tables}

1. Data Needs .................................. 6

2. Needs for IRP Tools $\ldots \ldots \ldots \ldots \ldots \ldots \ldots \ldots \ldots \ldots \ldots \ldots \ldots \ldots \ldots$

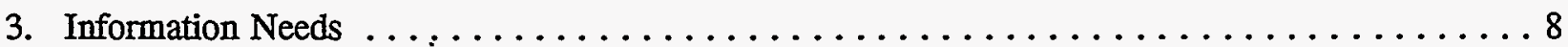




\section{List of Acronyms}

APPA

BPA

CARES

CEED

DEED

DOE

DSM

EPAct

IOU

IRP

JAA

NARUC

NCSL

NRECA

NREL

NWPPC

PMA

PUC

REA

RPG

SEPA

STEM

SWPA

TVA

WAPA
American Public Power Association

Bonneville Power Administration

Conservation and Renewable Energy System

Center for Energy Efficiency Data (EPRI)

Demonstration of Energy-Efficient Developments (APPA program)

U.S. Department of Energy

demand-side management

Energy Policy Act of 1992

investor-owned utility

Integrated Resource Planning

joint action agency

National Association of Regulatory Utility Commissioners

National Conference of State Legislatures

National Rural Electric Cooperatives Association

National Renewable Energy Laboratory

Northwest Power Planning Council

Power Marketing Administration

Public Utility Commission

Rural Electrification Administration ${ }^{*}$

Resource Planning Guide

Southeastern Power Administration

Short Term Energy Monitoring project

Southwestern Power Administration

Tennessee Valley Authority

Western Area Power Administration

*In December 1994, the REA became the Rural Utilities Service (RUS). The agency is referred to as REA throughout this document. 



\section{Introduction}

The nation's 3,000 publicly and cooperatively owned utilities ${ }^{1}$ have a documented need for assistance in integrated resource planning (IRP) and related strategic business planning practices. The availability of appropriate and sufficient assistance will be an important factor influencing the ability of these utilities to face the challenges and opportunities of today's competitive electric utility environment.

The U.S. Department of Energy (DOE) actively supports IRP advancement in the investor-owned utility (IOU) sector. This is accomplished through multiple vehicles, including grant funding to the state energy offices, to the National Conference of State Legislatures (NCSL), and to the National Association of Regulatory Utility Commissioners (NARUC). However, public utilities typically are not impacted by these DOE efforts. As consumer-controlled organizations, many publicly and cooperatively owned utilities are not regulated by state public utility commissions (PUCs).

To advance IRP as an essential approach for publicly and cooperatively owned utility operation in a drastically changing industry, DOE must develop additional vehicles of assistance, including the federal power agencies and key industry organizations such as the American Public Power Association (APPA) and the National Rural Electric Cooperatives Association (NRECA). DOE can reach the publicly/cooperatively owned utility sector by implementing the 5-year Strategy for Advancement of IRP in Public Power presented here. The program complements and furthers the Administration's public policy objectives. It is relevant and appropriate because it: .

- Builds upon and extends current IRP activities within the sector

- Reflects the participation and enthusiastic support of all key publicly and cooperatively owned utility industry players

- Is founded on 3 years of research on utility IRP activities and needs

- Will reach up to 3,000 utilities that face similar situations and have similar assistance needs.

The strategy described here was prepared by the National Renewable Energy Laboratory (NREL) and Garrick \& Associates under the sponsorship of DOE's Office of Utility Technologies. The overall strategy development approach involved four major tasks:

1. Establishing a Steering Committee composed of representatives from the federal power agencies, APPA, NRECA, and the Rural Electrification Administration (REA) to assist in the development of DOE's IRP Advancement Strategy. This committee evolved from the IRP Working Group established by a number of these organizations in 1992 to foster cross-fertilization, coordination, and joint project development;

2. Performing a Needs Assessment to determine publicly and cooperatively owned utility constituent needs, expectations, common interests, issues, and divergences that must be addressed by the IRP Advancement Strategy;

\footnotetext{
${ }^{1}$ Publicly owned utilities (also referred to as government-owned utilities) include state and municipal utilities and joint action agencies. Cooperatively owned utilities (also referred to as rural electric systems) include generation and transmission cooperatives and distribution cooperatives. While the publicly/cooperatively owned utility sector is very diverse, these utilities are all not-for-profit entities that are owned and controlled by their customers.
} 
3. Conducting extensive research of current publicly and cooperatively owned utility IRP practices and needs to provide a solid foundation for DOE's strategy. Research efforts included a statistically valid mail survey of the nation's publicly and cooperatively owned utilities, technical and economic market characterizations, telephone interviews with selected utilities, an assessment of federal and state IRP policies, and literature reviews; and

4. Formulating a strategy for DOE to address the needs identified during the preceding tasks. This strategy includes goals and objectives for a five-year IRP Advancement Program, as well as specific program initiatives and corresponding resource requirements and milestones.

The remainder of this document is organized into three sections: Background, Advancement Needs, and Action Plan. The Background section provides a brief profile of the publicly and cooperatively owned utility sector and summarizes the practice of IRP in this sector to date. The IRP advancement needs of the nation's 3,000 publicly and cooperatively owned utilities are presented next. The Action Plan delineates the goal and objective of the IRP advancement program. In addition, it presents specific program initiatives and outlines their associated resource requirements and schedule. The results of the Needs Assessment are provided in Appendix A. Appendix B presents the findings of the mail survey of publicly and cooperatively owned utilities. More than 20 federal and state IRP policies that affect publicly and cooperatively owned utilities are summarized in Appendix C. Appendix D presents a technical and economic market characterization of the sector. 


\section{Background}

IRP in the publicly/cooperatively owned utility sector is not as well established or understood as it is in the IOU sector. The structure of the publicly/cooperatively owned utility industry-characterized by a non-integrated, horizontal organization structure, complex relationships between utility systems, and consumer ownership and control-results in unique IRP practices and needs.

Publicly and cooperatively owned utilities account for more than $90 \%$ of the nation's electric utility systems and sell about $25 \%$ of U.S. electric energy. Some 1,800 municipal utilities account for the majority of these systems. Many of these municipal utilities have formed regional organizations (known as joint action agencies [JAAs]) to jointly build or finance generation and transmission systems, contract for power supply, and share other services. Currently, 38 joint action agencies supply partial- or fullrequirements power to municipal distribution systems. The publicly owned utility sector also includes ten federal power agencies, six state power authorities, and more than 100 "other" utilities, which include publicly owned utility districts, irrigation districts, Indian power authorities, and territorial power authorities. ${ }^{2}$

There are more than 950 rural electric systems in the United States, including 64 generation and transmission cooperatives (G\&T) and more than 880 distribution cooperatives. These utilities are consumer-owned cooperatives that are incorporated under the laws of the state in which they operate. The G\&Ts are responsible for supplying all of the power required by their distribution cooperative members (approximately 780 members). The 100 or so distribution cooperatives that are not members of a G\&T obtain power from other sources (e.g., federal power agencies, IOUs, self-generation, etc.).

In contrast to the IOU sector-where IRP occurs primarily due to regulatory requirements, IRP practice by publicly and cooperatively owned utilities is primarily driven by competition, resource acquisition needs, utility business objectives, and environmental considerations. Some publicly and cooperatively owned utilities also are impacted by federal and/or state IRP requirements. For example, the REA's policies and procedures shape rural electric cooperative resource planning practices, and 14 states have developed IRP rules that apply to one or more publicly and/or cooperatively owned utilities.

As expected, IRP is most prevalent among those utilities vested with resource planning responsibilities on behalf of member distribution systems. According to information obtained through the Public Power Survey performed as part of this project, more than $50 \%$ of the JAAs currently practice IRP, while a majority of G\&Ts also prepare IRPs. Approximately $25 \%(-500)$ of the nation's municipal utilities prepare an IRP for their system. Some of the others assist in the preparation of an IRP by a JAA supplier. Less than $10 \%$ of the nation's 900 distribution cooperatives prepare an IRP independent of a G\&T. Instead, most distribution cooperatives participate in the preparation of the G\&T's IRP.

In addition to IRPs prepared by individual utilities and by power suppliers and member distributors, regional planning is performed in the regions served by the Bonneville Power Administration (BPA) and the Tennessee Valley Authority (TVA). In the Pacific Northwest, the Northwest Power Planning Council (NWPPC) develops regional conservation and electric power plans in conjunction with BPA and its 120 publicly and cooperatively owned utility customers, the region's six IOUs, and other agencies that implement the plan. The NWPPC adopted its first IRP in 1983, with revisions in 1986 and 1991. In the early 1980s, the TVA also began practicing IRP to optimize the supply of electrical resources to its 160

\footnotetext{
${ }^{2}$ Refer to Scoping Study of Integrated Resource Planning Needs in the Public Utility Sector (NREL, June 1993) for a detailed profile of the public utility sector.
} 
full-requirements municipal and cooperative distributors. The Energy Policy Act of 1992 (EPAct, Section 113) reinforces TVA's IRP commitment by requiring the agency to conduct a least-cost planning program. TVA expects to complete an initial plan by December 1995.

BPA and TVA are the only federal power agencies with direct responsibility for planning and acquiring resources to meet their utility customers' loads. The Western Area Power Administration (WAPA), Southwestern Power Administration (SWPA), and Southeastern Power Administration (SEPA) sell only a portion of the electric power and energy required by most of their customers, who must plan for and acquire additional resources. ${ }^{3}$ As a result, these federal power agencies focus their IRP activities on encouraging and assisting customer IRP efforts. At the same time, WAPA has published a draft IRP rule (August 1994) that will ultimately affect some 400 publicly and cooperatively owned utilities in its 15-state region. The IRP requirement is mandated by Section 114 of EPAct. SEPA and SWPA are incorporating clauses that promote utility IRP practice into renewed power sales contracts.

IRP as it currently exists in the publicly/cooperatively owned utility sector is distinct from IRP practiced by IOUs. Given the unique utility responsibilities and complex interrelationships, it is likely that IRP in this sector also will evolve differently with respect to competition.

\footnotetext{
${ }^{3}$ WAPA supplies less than $30 \%$ of the electrical energy required by the majority of its customers, while SEPA and SWPA both provide less than $15 \%$.
} 


\section{Advancement Needs}

The IRP advancement needs of the nation's publicly and cooperatively owned utilities are overwhelming, with the vast majority of these 3,000 utilities needing additional resource planning assistance. This section documents these IRP advancement needs, including the type, priority, and magnitude of required assistance. Many of these needs are well known to those in the publicly/cooperatively owned utility industry, including the Steering Committee for this project. In addition, a number of these IRP needs were identified in the IRP Scoping Study performed by NREL in 1993. However, extensive research performed by NREL and Garrick \& Associates during 1993 and 1994 provides a more detailed and systematic understanding of IRP in this sector. Our findings regarding prioritized IRP needs and the publicly and cooperatively owned utilities requiring specific assistance provide a foundation for DOE to establish an advancement program for public power utilities.

The advancement needs of publicly and cooperatively owned utilities fall into six major areas, listed in priority order:

1. Data Development and Application

2. Analysis Tools

3. Information Dissemination

4. Financial Assistance

5. Technical Assistance

6. Other Needs

To a great extent, these needs reflect the financial and personnel constraints faced by most publicly and cooperatively owned utilities. The majority of these utilities have less than 50 employees. Thus, it is not surprising that "limited financial and personnel resources" was the most commonly cited barrier to IRP by respondents to NREL's public power survey.

\section{Data Development and Application}

More than any other type of assistance, respondents to NREL's public power survey cited the need for improved data for use in IRP analyses. The emphasis placed on data indicates that many publicly and cooperatively owned utilities are sufficiently involved in IRP to recognize that improved data are critical to sound decision making.

Current industry IRP data limitations reflect the difficulty and expense associated with data development, collection, and transfer. While a number of initiatives have been launched in recent years to enhance the quality and availability of IRP data, considerably more work is required, especially in the development of data that is tailored to the unique requirements of publicly and cooperatively owned utilities. Examples of data development initiatives include the establishment of the Electric Power Research Institute's Center for Energy Efficiency Data (CEED) and various projects being co-funded by WAPA, DOE, and others, including the development of demand-side management (DSM) performance validation guidebooks and the Short Term Energy Monitoring (STEM) project.

Table 1 presents a prioritized list of the types of data needed and the estimated number and percentage of U.S. publicly and cooperatively owned utilities desiring improved data in each of these categories. As shown, more than 2,000 utilities desire improved data on customer attitudes and behavior, while close to 2,000 desire improved data on DSM impacts, transmission and distribution (T\&D) options and economics, and customer facility/end-use characteristics. The data needs of power supply agencies are even more 
notable: more than $80 \%$ of JAAs and G\&Ts desire improved data on customer attitudes and behavior, DSM impacts, and customer facility/end-use characteristics.

Table 1. Data Needs

\begin{tabular}{lcc}
\hline \multicolumn{1}{c}{ Data Type } & Number & $\%$ \\
\hline 1. Customer Attitudes and Behavior & 2,040 & 70.4 \\
2. DSM Impacts & 1,991 & 68.8 \\
3. T\&D Options and Economics & 1,983 & 68.5 \\
4. Customer Facility and End-Use Characteristics & 1,914 & 66.1 \\
5. Regional Power Purchase Options/Costs & 1,621 & 56.0 \\
6. Externality Costs & 1,543 & 53.3 \\
\hline
\end{tabular}

1 Estimated based on the statistically valid survey sample extrapolated to the total population. Source: Public Power Survey, NREL and Garrick \& Associates, 1994.

\section{Analysis Tools}

The development of tools for publicly and cooperatively owned utility resource planning can help overcome IRP financial and personnel constraints. Tools can range from sophisticated software models to simple spreadsheets, as appropriate. Other types of tools include "turnkey" packages to facilitate implementation of innovative resource options.

The Resource Planning Guide (RPG) is an example of an analysis tool designed specifically for smallto medium-sized publicly and cooperatively owned utilities. Developed by Stone and Webster Management Consultants for WAPA (in conjunction with SWPA and SEPA), the RPG was first released in April 1994. To date, WAPA has invested more than $\$ 1.5$ million in the development of the $R P G$. Enhancement of the RPG will continue over the next 5 years or more, with DOE contributing funds toward its further development. The Evaluation Guidebook currently being developed by NREL for WAPA and SWPA is another example of an analysis tool designed specifically for publicly and cooperatively owned utilities.

As indicated in Table 2, half to two-thirds of all publicly and cooperatively owned utilities are interested in obtaining tools for various aspects of IRP, including load forecasting, DSM program selection, integrated supply-side and demand-side resource evaluation, impact and process evaluation, and externalities costing. Consistent with their distribution responsibilities, load forecasting tools are most desired by municipal utilities (71.5\%) and distribution cooperatives (56.3\%), followed by DSM program selection tools (68.1\% and 53.9\%, respectively). More than $80 \%$ of JAAs and G\&Ts desire tools for DSM program selection, supply-side and demand-side integration, and impact and process evaluation. Considerable interest in tools for the integration of wholesale and retail rate impacts was also expressed.

\section{Information Dissemination}

Information dissemination results in greater awareness and understanding of IRP principles by publicly and cooperatively owned utilities. Information needed on a range of IRP topics includes background information (e.g., What is IRP? What are the benefits of IRP?); how-to information; and information on various special topics (e.g., rates and IRP). 
A variety of mechanisms can be used to deliver information in the publicly and cooperatively owned utility sector, including publications, audiovisual materials, and workshops and seminars. Examples of current information services include IRP training workshops offered by WAPA, SWPA, and SEPA on the $R P G$ tool. APPA and SEPA are co-sponsoring the What Works in DSM manual and associated training courses. However, considerable opportunity exists to provide additional information services to a range of audiences, including utility staff, management, and policy makers.

Table 2. Needs for IRP Tools

\begin{tabular}{lcc}
\hline \multicolumn{1}{c}{ Types of Tools } & Number & $\%$ \\
\hline 1. Load forecasting & 1,948 & 67.3 \\
2. DSM Program Selection & 1,867 & 64.5 \\
3. Integrated Supply-Side and Demand-Side Evaluation & 1,725 & 59.6 \\
4. Impact and Process Evaluation & 1,490 & 51.5 \\
5. Externalities Costing & 1,476 & 51.0 \\
\hline
\end{tabular}

${ }^{1}$ Estimated based upon the statistically valid survey sample extrapolated to the total population. Source: Public Power Survey, NREL and Garrick \& Associates, 1994.

Almost $90 \%$ of the nation's JAAs and G\&Ts desire IRP-related information in the form of publications, along with more than $75 \%$ of municipal utilities and $60 \%$ of distribution cooperatives. This amounts to more than 2,000 utilities, as shown in Table 3. Workshops and seminars are the next-preferred format for obtaining IRP information, desired by more than $80 \%$ of JAAs and G\&Ts, along with about $70 \%$ of municipalities and $50 \%$ of distribution cooperatives. Other information interests include audiovisual materials, hotlines and clearinghouses, correspondence courses, and electronic bulletin boards.

\section{Table 3. Information Needs}

\begin{tabular}{lcc}
\hline \multicolumn{1}{c}{ Types of Information } & Number $^{1}$ & $\%$ \\
\hline 1. Publications & 2,085 & 72.0 \\
2. Workshops and Seminars & 1,847 & 63.8 \\
3. Audiovisual Materials & 1,643 & 56.7 \\
\hline
\end{tabular}

1 Estimated based upon the statistically valid survey sample extrapolated to the total population. Source: Public Power Survey, NREL and Garrick \& Associates, 1994.

\section{Financial Assistance}

Financial assistance supplements publicly and cooperatively owned utility financial resources by providing monetary support for IRP-related activities. Financial assistance is most applicable for cost-intensive aspects of IRP, such as analytical studies and implementation. Mechanisms for providing IRP-related financial assistance include grants, loans, cost-sharing, and incentives. APPA's Demonstration of EnergyEfficient Developments (DEED) grant program and the establishment of the Conservation and Renewable 
Energy System the Conservation and Renewable Energy System (CARES) ${ }^{4}$ by the Washington State Energy Office and local publicly owned utilities are examples of financial assistance approaches.

In the Public Power Survey, utilities expressed more interest in grants than any other type of financial assistance. Grants are desired by more than $60 \%$ of the utilities $(-1,800$ utilities), including more than $75 \%$ of JAAs and G\&Ts. Almost $50 \%$ of the utilities $(-1,350)$ are interested in cost-shared funding. Other types of financial assistance include collective funding by groups of utilities (of interest to approximately $40 \%$ of publicly and cooperatively owned utilities), awards, and loans.

\section{Technical Assistance}

Technical assistance supplements publicly and cooperatively owned utility personnel by providing one or more "experts" to guide and support IRP activities. Technical assistance is generally best applied to resource-intensive aspects of IRP or to areas requiring specialized expertise. Technical assistance mechanisms for advancing IRP include on-site consulting support, consultations with experienced peers, circuit riders (who share expertise among a number of small utilities), and demonstrations. The "Peermatch" program developed by WAPA and APPA during the 1980s and the WAPA's technical assistance program are examples of such services.

At present, roughly half of the nation's publicly and cooperatively owned utilities would like to obtain technical assistance for IRP activities. Greatest interest was shown in peer consultations, followed by onsite assistance and circuit riders.

\section{Other Needs}

A variety of other IRP assistance needs were identified by the project steering committee and staff. These needs include consistent IRP requirements, pricing reform, and federal transmission planning and access.

There is an overriding need for the development of consistent IRP requirements for publicly and cooperatively owned utilities. Some of these utilities currently must comply with two or more sets of IRP requirements, including those of the REA, a federal power agency, and/or a state PUC. Multiple requirements will become increasingly prevalent as more federal and state agencies establish IRP policies. Consistent IRP definitions and criteria, as well as reporting formats and submittal frequencies, are key to legitimizing the IRP process and reducing administrative burdens. Recommended approaches involve working with federal and state regulating agencies to coordinate efforts and develop consistent IRP requirements.

Pricing reform can help overcome IRP barriers that are particularly troublesome for non-vertically integrated publicly and cooperatively owned utility systems. Pricing reform approaches include aligning rates with cost-of-service and developing rate designs that are consistent with resource planning needs.

Federal power agencies such as WAPA, which owns and manages an extensive transmission grid, can help overcome barriers to publicly and cooperatively owned utility transmission access. Federal transmission planning can reflect IRP principles and consider customer needs. In addition, federal power grids can facilitate publicly and cooperatively owned utility access to alternative resources. For example, WAPA has provided customers with enhanced transmission access through a number of avenues, including line

4 CARES is a joint operating agency under Washington state statutes. It was established in 1992 to develop and acquire conservation, renewable, and high-efficiency energy resources as directed by its member utilities for the benefit of their customers. The agency bas the authority to issue revenue bonds with joint participation by member public utility districts and municipal utilities in Washington. 
extensions to alternative resource projects, purchase of renewable energy project power, and contractual agreements with customers to increase their access to resource options. 


\section{Action Plan}

This section presents an Action Plan for DOE to implement a 5-year Advancement of IRP in Public Power program in collaboration with other federal entities, including REA, the federal power agencies, and the various publicly and cooperatively owned utility organizations. The action plan was developed and adopted by the Advancement of IRP in Public Power Steering Committee in 1994. It delineates the program goal and objective, as well as specific IRP advancement initiatives. In addition, it presents the resource requirements and schedule associated with satisfying the program's goal.

\section{Goal and Objective}

The following program goal has been adopted by the IRP Advancement Steering Committee:

The goal of the 5-year Advancement of IRP in Public Power program is to assist the nation's publicly and cooperatively owned utilities to provide low-cost, reliable, efficient utility service to their consumers by advancing sound strategic business and resource planning practices for addressing the opportunities and uncertainties of competition.

In support of this goal, the following program objective has also been adopted:

The' program's objective is to develop, demonstrate, and widely deploy enhanced services and tools for business and resource planning to augment human, financial, and technical resources of publicly and cooperatively owned utilities.

\section{Initiatives}

Specific initiatives to advance IRP under this program involve the development, demonstration, and deployment of data support, IRP tools, information support, financial and technical assistance, and other assistance. The following is an initial list of priority initiatives that the program seeks to accomplish given the availability of sufficient funding:

\section{Data}

- Sponsor market/data research on customer attitudes, behavior, and facility/end-use characteristics; DSM costs and benefits; transmission and distribution options and economics; etc.

- Develop guidelines and procedures for local utility data development, including accurate use and transferability of national and regional data and local utility data acquisition.

- Establish national and regional centers to produce and disseminate IRP data that are particularly tailored for publicly and cooperatively owned utilities. 


\section{Tools}

- Support the development and distribution of improved load forecasting tools and methods.

- Support the production and application of tools for DSM program selection, including appropriate screening methods, analysis tools, etc.

- Assist in the development and distribution of supply-side and demand-side resource integration tools that are matched to the varying needs and capabilities of the nation's publicly and cooperatively owned utilities.

\section{Information}

- Develop and disseminate a series of IRP publications to inform publicly and cooperatively owned utility personnel about IRP issues, approaches, etc.

- Develop training curricula and materials for introductory and advanced IRP seminars.

\section{Financial and Technical Assistance}

- Provide grants and/or cost-shared funding for utility resource planning, implementation, and evaluation projects on a limited, case-study basis.

- Support and promote collective funding initiatives, including providing education and technical and financial assistance.

- Increase the availability of peer consultation and on-site assistance services.

\section{Other}

- Formulate accepted "minimum IRP standards" to promote consistency among IRP policies and approaches.

\section{Resources}

Both infrastructure and budgetary resources are required to accomplish the initiatives listed above. Infrastructure encompasses program decision-making and administration, including program personnel and mechanisms for delivering IRP services and tools to thousands of publicly and cooperatively owned utilities. Budgetary resources support the infrastructure and provide for the development, demonstration, and deployment of IRP services and tools.

\section{Infrastructure}

The recommended infrastructure for the program consists of a Steering Committee, a central administrative body, and existing publicly and cooperatively owned utility industry delivery mechanisms. The program decision-making authority will be vested in a Steering Committee made up of the Steering Committee representatives, with the possible addition of selected utility representatives. At the same time, central, dedicated program administration and staffing is necessary to successfully implement the program. Critical functions of this central administrative body will include daily program administration, communication with stakeholders and decision-makers, information gathering and dissemination, and securing of services 
(i.e., procurement and oversight). In addition, the administrative body will develop and deploy IRP services and tools, as required.

The staff support organization will work closely with participating utility organizations to develop and deploy the various IRP services and tools. This includes assisting in the development or enhancement of services and tools (e.g., providing funding to APPA to expand the "What Works in DSM" manual), as well as disseminating these services and tools via existing delivery mechanisms (e.g., NRECA's training program). Because extensive delivery mechanisms are currently in place for reaching publicly and cooperatively owned utilities, program resources can be focused on the development of enhanced services and tools.

The varying needs of particular subsectors of publicly and cooperatively owned utilities will be identified and targeted in the deployment of program services and tools. For example, program services and tools will be adapted to address unique utility needs that are attributed to various factors such as utility ownership type, geographic location, and contractual situation. In addition, publicly and cooperatively owned utilities that have a significant need for help will be targeted for priority assistance. For example, planning tools will be offered most aggressively to utilities in regions with a current need for new resources or those that are approaching load/resource balance. Other targets for IRP advancement are utilities with high supplemental supply costs or those facing stringent air quality or other environmental requirements. Another deployment approach involves providing priority assistance to selected utility "leaders" to successfully implement IRP. These models of success provide a foundation for educating and assisting other publicly and cooperatively owned utilities in the adoption of IRP practices.

\section{Budget}

Budgetary resources are needed to support the program infrastructure and to fund the development of enhanced IRP services and tools for publicly and cooperatively owned utilities. The magnitude of available program funding will determine the breadth and depth of program initiatives, and program accomplishments will be commensurate with funding levels. Limited initiatives, such as modification of existing services and products for wider deployment, can be accomplished within a small program budget (e.g., less than $\$ 1$ million/per year), while more significant IRP advancement efforts such as data and tools development will require a larger program budget. Considering the size of the program audience-potentially thousands of utilities-and the magnitude of their needs, in-depth execution of this program requires substantial budgetary commitments. These budgetary resources can best be acquired through multi-year DOE program funding leveraged with in-kind and cost-shared contributions from the various Steering Committee organizations.

\section{Schedule and Milestones}

The Advancement of IRP in Public Power program will be implemented over a 5-year period, with the first year dedicated to program organization and initial implementation. Milestones associated with the first year of the program include:

- Establishing a charter for Steering Committee membership and decision-making;

- Inventorying existing IRP-related services and tools offered by Steering Committee organizations and others;

- Enhancing selected high-priority services and tools for increased applicability across the publicly and cooperatively owned utility sector; 
- Widely distributing existing and enhanced products and services using existing distribution channels (i.e., via participant organizations' established distribution mechanisms); and

- Planning for implementation of the program in years 2 through 5, including detailed delineation of new products and services to be developed and establishment of an evaluation plan for assessing program impacts.

The program workplan will be executed during years 2 through 5 of the program. The program will be continuously monitored and evaluated to assess program infrastructure and delivery services and to quantify the impact of the IRP advancement services. The research completed to date by NREL and Garrick \& Associates on IRP activities of publicly and cooperatively owned utilities provides an excellent baseline from which to determine program impacts at the end of the 5-year program. 


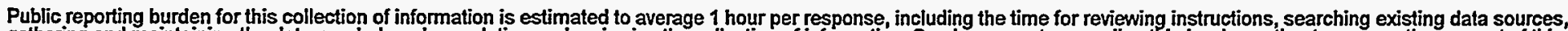

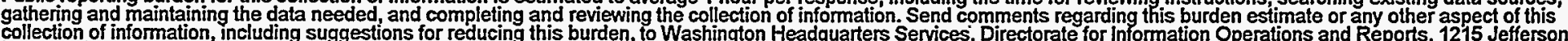

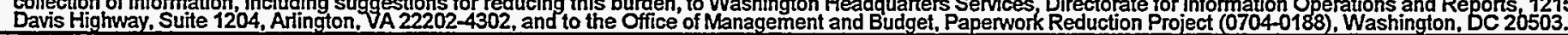
1. AGENCY USE ONLY (Leave blank)
2. REPORT DATE
October 1995
3. REPORT TYPE AND DATES COVERED Subcontractor report

4. TITLE AND SUBTITLE Strategy for Advancement of IRP in Public Power-Volume 1: IRP Advancement Strategy

5. FUNDING NUMBERS

AS115504

6. AUTHOR(S)

Cynthia J. Garrick

Subcontract AAW-3-13353-01

7. PERFORMING ORGANIZATION NAME(S) AND ADDRESS(ES)

Garrick \& Associates

8. PERFORMING ORGANIZATION

6188 Willow Springs Drive

Morrison, Colorado 80465

REPORT NUMBER

9. SPONSORING/MONITORING AGENCY NAME(S) AND ADDRESS(ES)

National Renewable Energy Laboratory

1617 Cole Boulevard

Golden, CO 80401-3393

SP. SPONSORINGMONITORING
AGENCY REPORT NUMBER

TP-461-7282

11. SUPPLEMENTARY NOTES

DE95009227

12a. DISTRIBUTION/AVAILABILITY STATEMENT

National Technical Information Service

U.S. Department of Commerce

5285 Port Royal Road

Springfield, VA 22161

12b. DISTRIBUTION CODE

UC

1320

13. ABSTRACT (Maximum 200 words)

This subcontractor report, prepared for the U. S. Department of Energy (DOE), presents a 5-year strategy to advance integrated resource planning (IRP) among publicly and cooperatively owned utilities. The strategy builds on and extends current IRP, reflects the support of key publicly and cooperatively owned utilities, and is based on 3 years of research on utility IRP activities and needs. The strategy is intended to reach out to as many as 3000 utilities. The overall strategy development involved four major tasks: (1) establishing a steering committee composed of representatives from the federal power agencies and industry organizations, (2) performing a needs assessment to determine constituent needs, expectations, common interests, issues, and divergences that need to be addressed, (3) extensively researching the IRP practices and needs of publicly and cooperatively owned utilities, and (4) formulating a strategy for DOE to address the needs identified in the preceding tasks. The report provides a brief profile of the publicly and cooperatively owned utility sector and summarizes the IRP practices of this sector. It also discusses what is needed to advance IRP in this sector. The needs identified fell into six areas: data development and application, analysis tools, information dissemination, financial assistance, technical assistance, and other needs. The report also contains an action plan delineating the goal and objective of the IRP advancement program. Volume 2 of this report consists of appendices that contain needs assessment results, mail survey findings, summaries of federal and state IRP policies, and technical and economic market characterizations.

SUBJECT TERMS integrated resource planning; public power; public utilities; utility cooperatives

15. NUMBER OF PAGES 20

16. PRICE CODE

17. SECURITY CLASSIFICATION OF REPORT unclassified
18. SECURITY CLASSIFICATION OF THIS PAGE unclassified
19. SECURITY CLASSIFICATION OF ABSTRACT unclassified
20. LIMITATION OF ABSTRACT UL 

